\title{
Failure analysis of prestressed anchor bars
}

\author{
M. Elices ${ }^{\mathrm{a}, *}$, A. Valiente ${ }^{\mathrm{a}}$, L. Caballero ${ }^{\mathrm{a}}$, M. Iordachescu ${ }^{\mathrm{a}}$, J. Fullea ${ }^{\mathrm{b}}$, J. Sánchez-Montero ${ }^{\mathrm{b}}$, \\ $V$. López-Serrano ${ }^{c}$
}

\begin{abstract}
A B S T R A C T
Three broken steel bars from a sewed crack in a dam are reported. The inspection of the fracture surfaces of the prestressed bars suggests that fractures were triggered by small cracks and by the inherent brittleness of the bars, as fracture toughness was about $40 \mathrm{MPa} \mathrm{m}^{1 / 2}$. The analysis of the failures shows that the usual design requirements for prestressing bars fail to warn against brittle failures if some damage exists. Some recommendations, based on the concept of damage tolerance, are suggested to avoid similar unfortunate incidents.
\end{abstract}

\section{Introduction and background information}

The reported failures occurred in a mended crack from a vault dam. This crack was sewn using steel bars anchored in the dam basement, stressed, and clamped on the downstream side. After 10 years of performance, three broken bars were detected during a routine inspection.

To sew the crack, 340 bars $-36 \mathrm{~mm}$ diameter and $7.5 \mathrm{~m}$ length-were used. The length of the anchorage was $3 \mathrm{~m}$ and the free length of the bar, protected with a plastic sheath, was $4.5 \mathrm{~m}$. All fractures took place inside the free length. Sketches of the prestressed anchor bars and the location of fractures are shown in Fig. 1.

The broken bars were found on the floor, near to the downstream side. The fracture surface of two of them (hereafter called A and B bars) was slightly corroded, as they had remained on the ground for some days. The third one (called the $\mathrm{C}$ bar) was found just after failure. Therefore, as it was not corroded it enabled a more accurate evaluation of the fracture sources.

These anchor bars, once stressed, remained as such forever. Under these high stresses-about $900 \mathrm{MPa}$ or 0.7 uts (ultimate tensile stress)-they are very susceptible to small damage. Surface scratches, cracks, pits or notches-that will not usually affect the performance of bars of concrete reinforcement-may become dangerous when present in prestressed bars. In fact, the fractures reported in this paper were triggered by very small surface cracks.

The purpose of this study is to illustrate such a fact. Three failures of post-tensioning bars with surface damage are analysed using the tools of Fracture Mechanics and some procedures, based on the concept of damage tolerance, are suggested to avoid similar accidents, as reported in analogous papers in this journal [1,2]. 

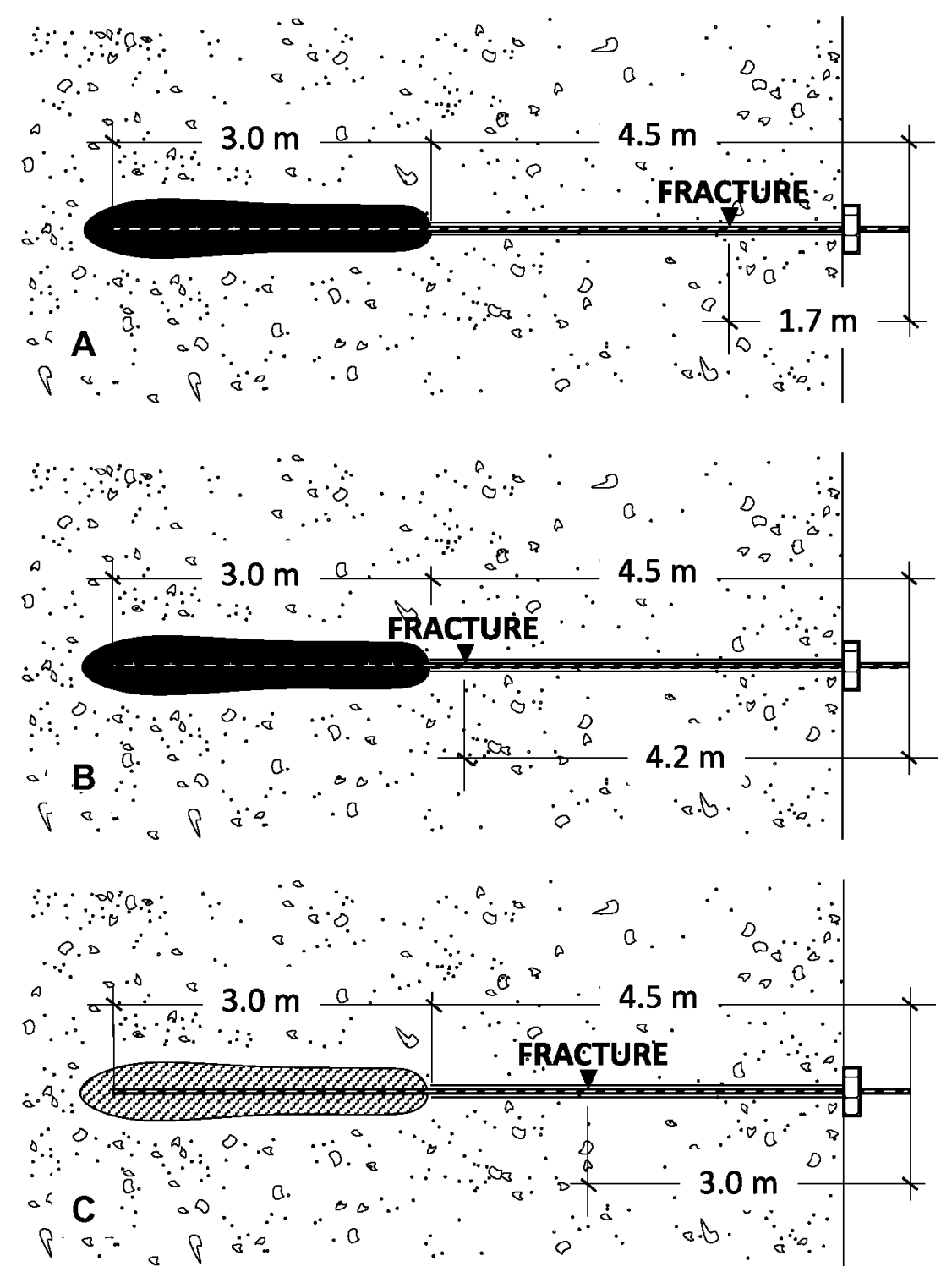

Fig. 1. Sketches of the anchor bars and the place of reported fractures.

Table 1

Chemical composition of prestressing bars.

\begin{tabular}{lllllll}
\hline Bar & $\mathrm{C}(\%)$ & $\mathrm{Mn}(\%)$ & $\mathrm{Si}(\%)$ & $\mathrm{P}(\%)$ & $\mathrm{S}(\%)$ & \\
\hline $\mathrm{A}$ & 0.70 & 1.50 & 0.69 & 0.012 & $<0.010$ \\
$\mathrm{~B}$ & 0.75 & 1.52 & 0.70 & 0.013 & 0.010 \\
$\mathrm{C}$ & 0.69 & 1.49 & 0.70 & 0.015 & $<0.010$ & 0.26 \\
\hline
\end{tabular}

\section{Anchor bar characterisation}

\subsection{Chemical and microstructural analysis}

Chemical composition, determined by spectrometry, of the broken bars is shown in Table 1 . This chemical composition corresponds approximately to that of AISI grade 1070 with slightly higher manganese levels.

Microstructural analysis was carried out on a cross section of the bar, etched in $2 \%$ nital. Microstructure was ferrite-pearlitic, with dominance of fine pearlite due to the relatively high carbon content (see Fig. 2a). 

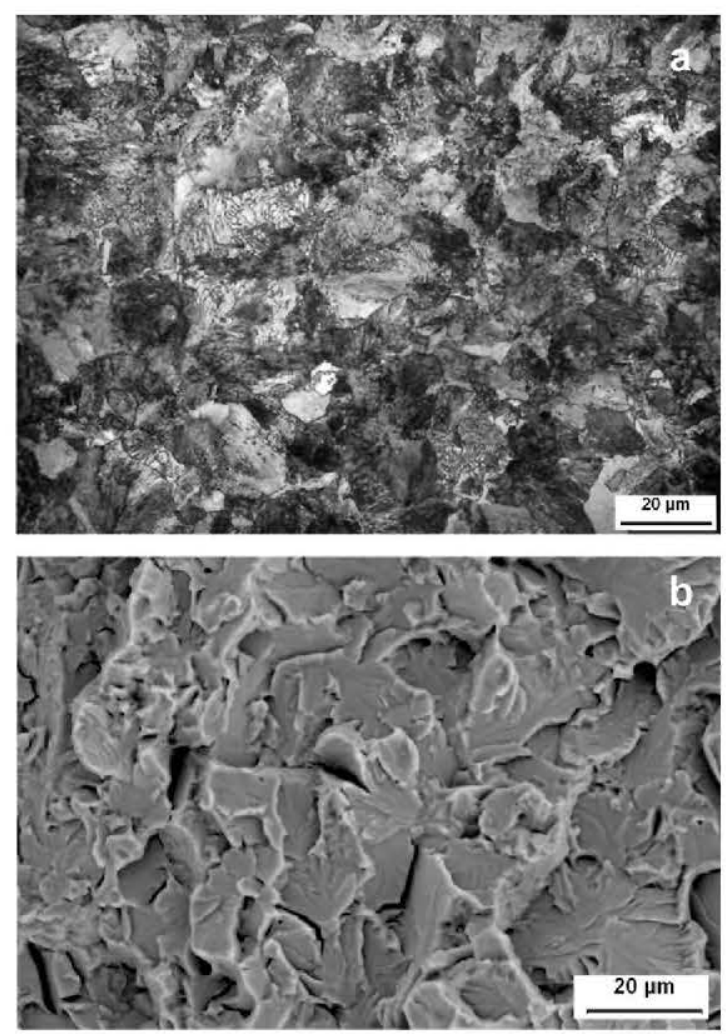

Fig. 2. (a) Bar microstructure; fine pearlite, (b) fracture surface, far from the initiation point, shown predominance of cleavage.
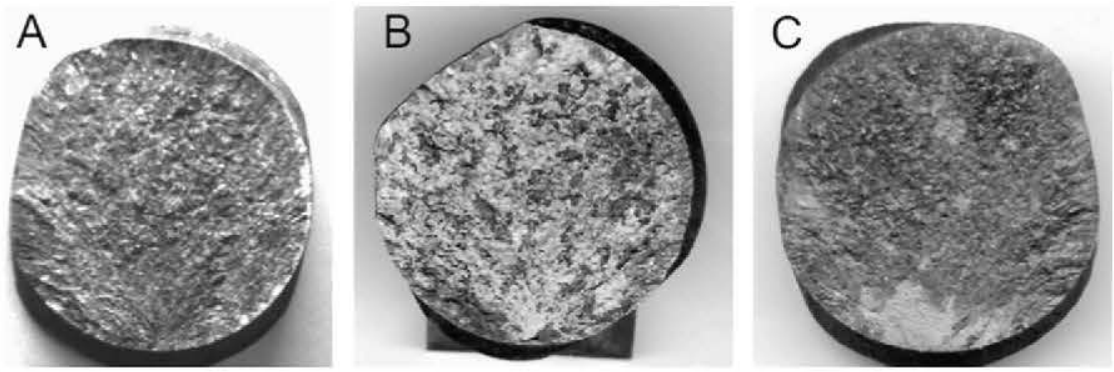

Fig. 3. Fracture surfaces of the broken bars.

\subsection{Fractography}

Fig. 3 shows the available fracture surfaces of the three broken bars. Fracture surfaces of bars A and B were corroded, as they were found on the ground some time after the rupture. The fracture surface of bar $\mathrm{C}$ was cleaner, as rupture had happened a few days before.

Fracture surfaces were chemically washed and examined both by optical microscopy and by scanning electron microscopy (SEM). Optical microscopy reveals, in each sample, a fan of marks starting from a point at the surface; this is a clear sign that fracture started at a surface defect. SEM, far from that point, displays predominance of cleavage, a characteristic feature of brittle fracture (Fig. 2b). Near the defect, SEM shows a granular aspect, an indication of fracture assisted by corrosion. Most probably, a microcrack will have grown slowly by a process of corrosion aided by the tensile stress up to a critical value where fast brittle fracture took place. Fig. 4 shows a plausible border between both types of fracture surface. Fig. 4a belongs to bar B and Fig. $4 \mathrm{~b}$ to bar C.

Additional examination, looking for secondary cracks on the surface, was performed in longitudinal sections near the three broken samples. Optical microscopy disclosed small cracks, perpendicular to the surface, between 0.3 and $0.5 \mathrm{~mm}$ depth. Further analysis, using X-ray diffraction spectroscopy, showed corrosion products inside of them. 

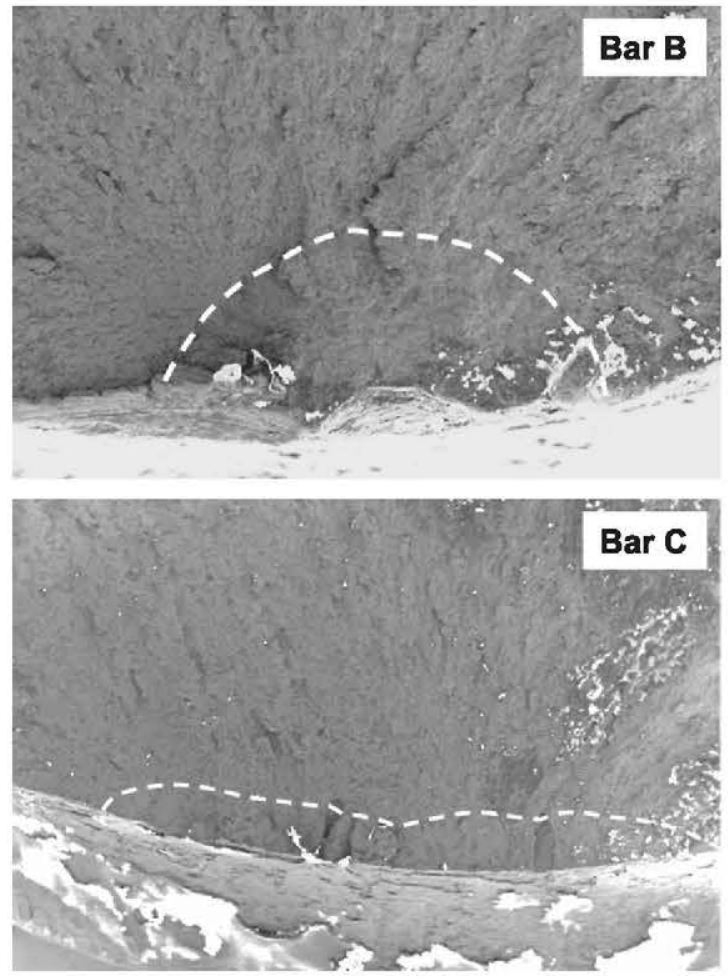

Fig. 4. Initial cracks from bars B and C.
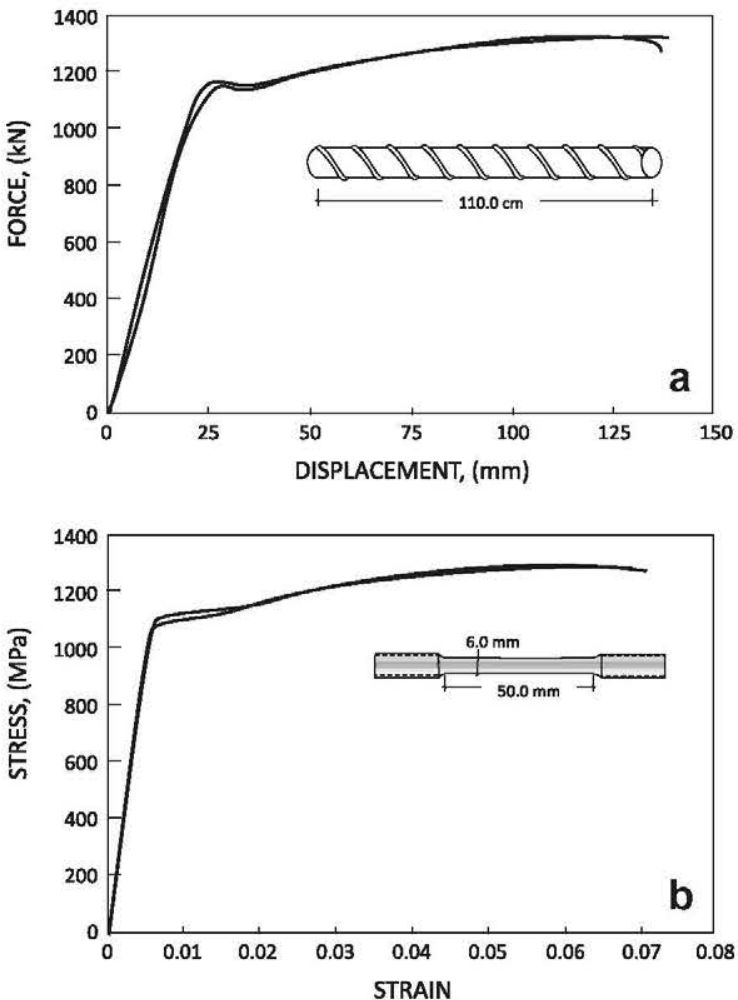

Fig. 5. (a) Load-displacement curves for bars, (b) stress-strain curves for sub-sized specimens. 
Table 2

Mechanical properties of sub-size specimens.

\begin{tabular}{llllll}
\hline Specimen & $R_{0.2}(\mathrm{MPa})$ & $R_{\mathrm{m}}(\mathrm{MPa})$ & $\varepsilon_{\mathrm{m}}(\%)$ & $\Delta(\%)$ & $E(\mathrm{GPa})$ \\
\hline 1 & 1096 & 1295 & 6.7 & 29 & 219 \\
2 & 1120 & 1306 & 6.1 & 26 & 206 \\
3 & 1107 & 1301 & 6.6 & 28 & 195 \\
4 & 1122 & 1302 & 6.6 & 27 & 193 \\
Average values & $1096 \pm 6$ & $1295 \pm 2$ & $6.5 \pm 0.1$ & $28 \pm 2$ & $203 \pm 6$ \\
\hline
\end{tabular}
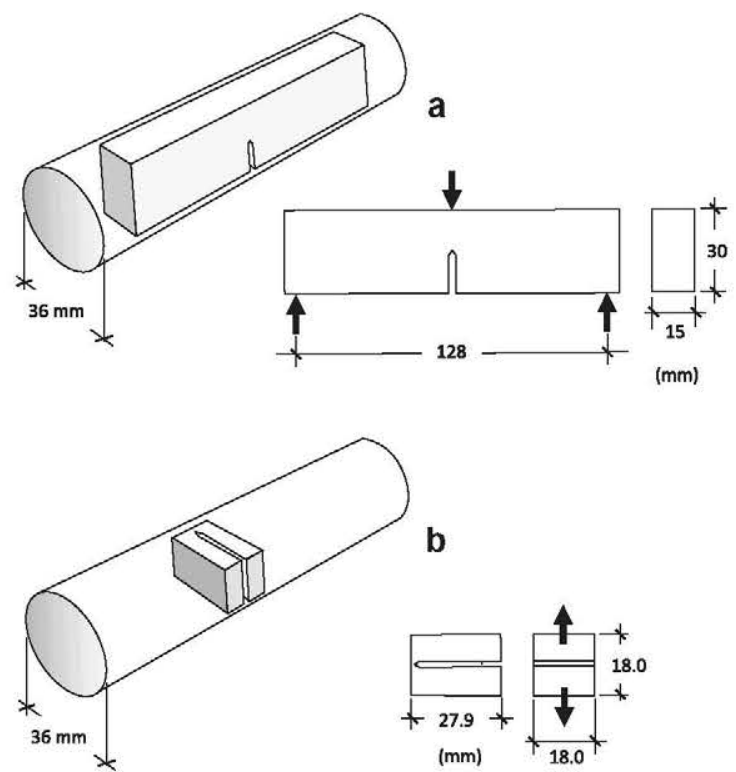

Fig. 6. Geometry of the specimens used to measure bar fracture toughness; according to ASTM E399 (a) and to ASTM 1304 (b).

\subsection{Tensile tests}

Tensile testing was carried out in accordance with ISO 15630-3 [3]. Two types of specimens were tested: bar samples$1.1 \mathrm{~m}$ length and $36 \mathrm{~mm}$ diameter-from the broken rods, and sub-size specimens-50 $\mathrm{mm}$ length and $6 \mathrm{~mm}$ diameter (see inset in Fig. 5b)-also from the broken bars.

Fig. 5 depicts the representative results of load-displacement curves for bar samples and stress-strain curves for sub-size specimens. Table 2 shows yield stress $\left(R_{0.2}\right)$, maximum stress $\left(R_{\mathrm{m}}\right)$, strain under maximum load $\left(\varepsilon_{\mathrm{m}}\right)$, reduction of area $(A)$ and modulus of elasticity $(E)$ for the sub-size specimens.

Results from both tests are in agreement. See, for example, fracture loads; from full-size specimens, the average rupture load was $1320 \mathrm{kN}$ and the computed value from sub-size specimens was $1318 \mathrm{kN}$ (from the average value of $1295 \mathrm{MPa}$ and a circular surface of $36 \mathrm{~mm}$ diameter).

\subsection{Fracture tests}

Fracture toughness was measured following standards ASTM E 399 [4] and ASTM E 1304 [5]. Single Edge Bend Specimens (SEBS), with $15 \mathrm{~mm}$ thickness, were used according to ASTM E 399, and Short Bar Specimens (SBS), of $18 \mathrm{~mm}$ thickness, according to ASTM E 1304. Fig. 6 shows the geometry of these samples and the position of the bar from which they were extracted; in both samples the crack plane was transversal to the bar axis in order to reproduce the same propagation plane as in the failed bars.

Experimental results from SBS and SEBS samples are shown in Table 3. No more tests were performed with SBS samples in view of the small scattering in the recorded toughness values. Testing SEB specimens posed some problems, this is why a single representative value is recorded.

When machining SEB samples, a delicate step is to create a fatigue crack at the end of the specimen notch, particularly if the sample material is very brittle because as soon as the crack is formed it propagates and the sample breaks during the fatigue phase. As the norm requires some initial crack shape and depth before testing, sometimes this particular shape is 
Table 3

Fracture toughness of steel bars.

\begin{tabular}{lllll}
\hline Specimen & ASTM standard & \multicolumn{2}{l}{ Fracture toughness } \\
\hline Short bar specimen (SBS) & E 1304 & 41.4 & 38.5 & 40.5 \\
Single edge beam (SEBS) & E 399 & $41.0^{\mathrm{a}}$ & - & - \\
\hline
\end{tabular}

${ }^{a}$ See text.
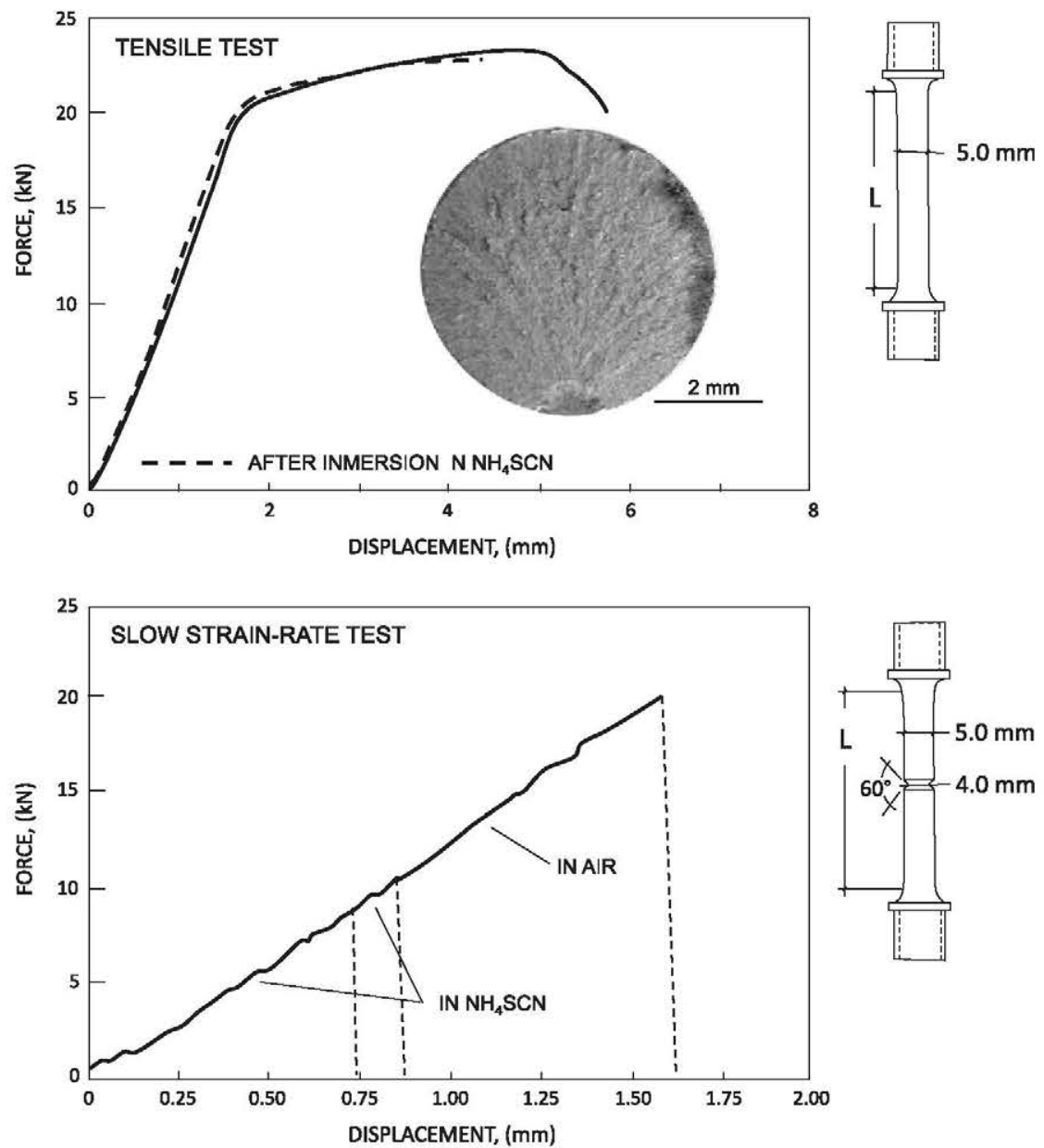

Fig. 7. (a) Tensile tests with small-sized samples in air and after $48 \mathrm{~h}$ immersion in $\mathrm{NH}_{4} \mathrm{SCN}$, (b) slow strain-rate tests with notched small sized samples in air and in $\mathrm{NH}_{4} \mathrm{SCN}$.

difficult to achieve. This was the problem found when machining SEB specimens with the available material provided for this research. In some samples it was possible to generate a fatigue crack, but unfortunately its geometry did not conform with standard requirements. Even so, the computed toughness from the experimental data provided values of about $41 \mathrm{MPa} \mathrm{m}^{1 / 2}$. A detailed account of computing toughness from a SEB sample with a corner crack is shown in Appendix. Nevertheless, the measured small values of the fracture toughness, about $40 \mathrm{MPa} \mathrm{m}^{1 / 2}$, are indicative of brittle behaviour.

\subsection{Corrosion tests}

The high strength of these bars, coupled with the high tensile stress to which they are subjected to prestress the crack dam, raise questions as to the possibility of environmentally assisted cracking and, particularly, hydrogen embrittlement. To assess the susceptibility of these steels to hydrogen embrittlement a test, which determines the time to fracture of a sample maintained at a constant tensile force and immersed in a solution of ammonium thiocyanate $\left(\mathrm{NH}_{4} \mathrm{SCN}\right)$, was proposed by FIP (Federation International of Prestressed Concrete). For details see [3,6].

Small-sized samples, as shown in the inset of Fig. 7a were subjected to a tensile force of $19.2 \mathrm{kN}$ ( $80 \%$ of uts) in a solution of $\mathrm{NH} 4 \mathrm{SCN}$ at $50^{\circ} \mathrm{C}$, for $48 \mathrm{~h}$. Later on, the samples were tensile tested in air. Representative results are shown in Fig. 7a 
jointly with a standard tensile test in air. As can be noted, the aggressive environment has produced some degree of embrittlement, as the end of the load-displacement curve when tested in air disappeared. Moreover, an analysis of the fracture surfaces of the broken samples once immersed in the $\mathrm{NH}_{4} \mathrm{SCN}$ solution showed small cracks that triggered the fracture.

In addition, small strain rate tests with notched samples in air and in $\mathrm{NH}_{4} \mathrm{SCN}$ were performed. The results are summarised in Fig. 7b. Sample geometry is shown in the inset. Tests were conducted at $0.0004 \mathrm{~mm} / \mathrm{min}$. As can be noted, tests carried out inside the aggressive environment are more brittle, a clear support of the susceptibility to hydrogen embrittlement of these steels.

\section{Failure analysis}

\subsection{Traditional approach}

Steel bars were loaded at $750 \mathrm{kN}, 70 \%$ of the nominal ultimate strength $1070 \mathrm{kN}$, or about $0.57 \%$ of the experimental rupture load.

The dam was fully instrumented, particularly near the crack, and no overloads were detected from the placement of the anchorages. Neither the small reduction of area due to the discovered cracks in the broken section gives reasons for the ruptures.

These assessments show that the usual requirements for prestressing bars-i.e., yield strength, ultimate tensile strength and ductility-are not enough to warn against brittle failures if the risk of damage has to be considered. Here, the mechanical properties (displayed in Table 2) were higher than those required by the standards and, in spite of this, fracture occurred.

\subsection{Damage tolerance approach}

From the analysis of the broken bars it seems that fractures were triggered by small cracks starting at the bar surface. Also, the brittle aspect of the fracture surfaces and the low value of the fracture toughness (about $40 \mathrm{MPa}^{1 / 2}$ ) suggest that linear elastic fracture mechanics is the simplest tool to analyse such failures. To this end, the stress intensity factors for the surface cracks were computed and, jointly with the measured fracture toughness, certain insights about the failed bars are reported.

The surface cracks of bars B and C (see Fig. 4) can be modelled as elliptical cracks, as sketched in the inset of Fig. 8 ( $a$ and $b$ are the ellipse semi-axes). The stress intensity factor for this geometry was numerically computed in 1976 by Astiz [7,8] and also by photoelastic techniques by the authors [9]. When $b>a$ the maximum stress intensity factor is at point A (see Fig. 9) and its value can be expressed as

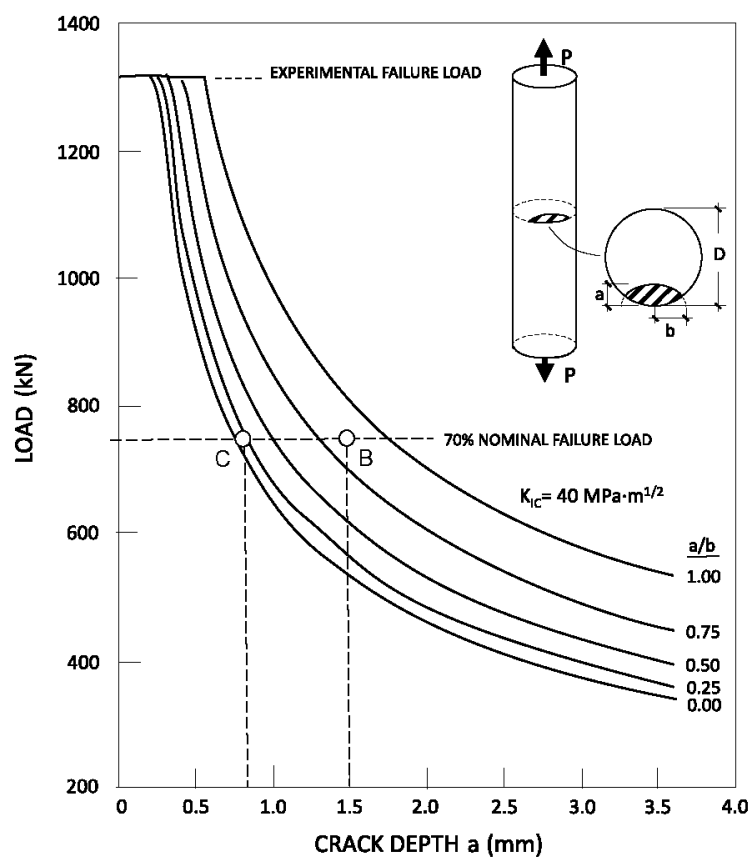

Fig. 8. Diagram of fracture loads as a function of crack depth for semi elliptical cracks. Bar of $36 \mathrm{~mm}$ diameter and $K_{J C}=40 \mathrm{MPa} \mathrm{m}^{1 / 2}$. Failure of bars B and C are shown in the figure. 


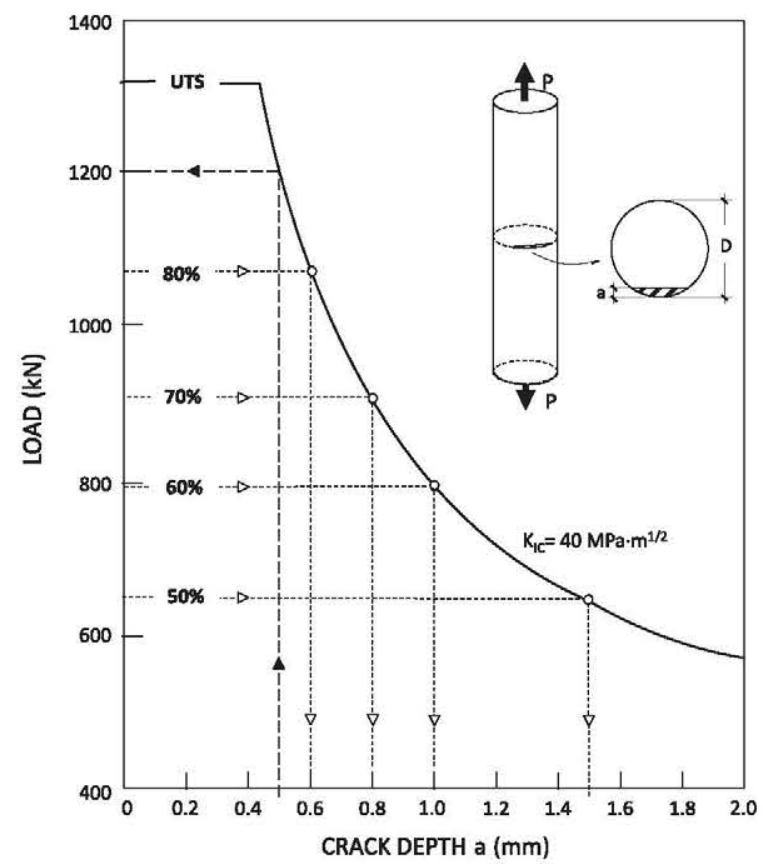

Fig. 9. Diagram of fracture loads as a function of crack depth for straight front cracks. Critical crack depths and critical overloads are shown under different assumptions.

Table 4

Values of $C_{i j}$.

\begin{tabular}{llrrr}
\hline$C_{i j}$ & $j=0$ & \multicolumn{1}{c}{1} & \multicolumn{1}{c}{2} & \multicolumn{1}{c}{3} \\
\hline$i=0$ & 1.118 & -0.179 & -0.339 & 0.130 \\
$i=2$ & 1.405 & 5.902 & -9.057 & 3.032 \\
$i=3$ & 3.891 & -20.370 & 23.217 & -7.555 \\
$i=4$ & 8.328 & 21.895 & -36.992 & 12.676 \\
\hline
\end{tabular}

$$
K_{1}(P, a, b, D)=\frac{4 P}{\pi D^{2}} \sqrt{\pi a} \sum \sum C_{i j}\left(\frac{a}{b}\right)^{i}\left(\frac{a}{b}\right)^{j}
$$

where $P$ is the applied load and $D$ is the bar diameter. The coefficients $C_{i j}$ are given in Table 4 . Ref. [10] provides more general expressions and a survey of the stress intensity factors for this crack configuration is given in [11].

When Linear Elastic Fracture Mechanics is applicable, the rupture load $P$ can be deduced from

$$
K_{1}(P, a, b, D)=K_{I C}
$$

Taking into account (1), the rupture load is given by:

$$
P=\frac{D \sqrt{\pi D}}{4} K_{I C} \cdot M\left(\frac{a}{D}, \frac{a}{b}\right)
$$

where the non-dimensional function $M(a / D, a / b)$ can be computed from (1). For small values of $a / D$ and $a / b$ (shallow cracks with almost straight front) this function can be approximated by

$$
M(\xi)=\xi^{-1 / 2} \cdot\left(1.0806+0.6386 \xi-2.444 \xi^{2}+13.463 \xi^{3}\right)^{-1}
$$

where $\xi=a / D$, as shown by Valiente [12].

Fig. 8 shows a plot of rupture loads $P$ as a function of crack depth $a$ for steel bars of $36 \mathrm{~mm}$ diameter and with fracture toughness of $40 \mathrm{MPa} \mathrm{m}^{1 / 2}$.

Fracture surfaces, shown in Fig. 4a and b, suggest corrosion cracks with values of $a$ of about $1.5 \mathrm{~mm}$ (for bar B, Fig. 4a) and $0.8 \mathrm{~mm}$ (for bar $C$, Fig. $4 \mathrm{~b})$. The last one is a crack with an almost straight front $(a / b=0.1)$, while the first approaches a circular crack (as $a / b=0.8$ ).

Fig. 8 also shows that for a crack of roughly straight front and a depth of $0.8 \mathrm{~mm}$ (the broken bar C), the rupture load is $750 \mathrm{kN}$, which corresponds to the specified load of the prestressed bar. Likewise, the rupture load of a circular crack $1.5 \mathrm{~mm}$ depth (the broken bar B) is also $750 \mathrm{kN}$. 
This approach shows accurately the failure loads of the prestressed bars as a function of the crack depth $a$ and the aspect ratio $a / b$. The curves, in Fig. 8, come from equating the stress intensity factor of Eq. (1) to the measured value $40 \mathrm{MPa}^{1 / 2}$ of the fracture toughness. Therefore, it seems that a damage tolerance analysis based, in this case, on Linear Elastic Fracture Mechanics provides a plausible explanation of the bar ruptures.

A further confirmation of these results came from the analysis of the broken specimen after being immersed in $\mathrm{NH}_{4} \mathrm{SCN}_{\text {. }}$ As already noted, broken samples display small semi-elliptical cracks of depth $a=0.3 \mathrm{~mm}$ and aspect ratio $a / b=0.6$. A reasoning similar to the previous one, for bars of $5.0 \mathrm{~mm}$ diameter, gives a fracture load of $24 \mathrm{kN}$, similar to $23 \mathrm{kN}$ found during the test (see Fig. 7a).

\section{Discussion and recommendations}

The above analysis was based on two hypotheses:

a. The presence of surface defects in the bars, that can be modelled as semi-elliptical cracks perpendicular to the surface, as shown in Fig. 3.

b. The brittle nature of the bar fractures, substantiated by the low values of fracture toughness of about $40 \mathrm{MPa} \mathrm{m}^{1 / 2}$.

From such assumptions, some discussions concerning the critical crack depths or critical overloads can be explored:

The critical crack depth that triggers fracture can be computed from Eq. (2). For shallow cracks, as a first approximation, it suffices to consider cracks with straight fronts and use expression (4). This evaluation can be improved using Eq. (1) or references given in [10]. The results are shown in Fig. 9 for different loadings, where the bar ultimate tensile strength uts is $1320 \mathrm{kN}$. The critical crack depths when the bar is loaded at $80 \%, 70 \%, 60 \%$ and $50 \%$ of the uts are, respectively $0.6,0.8$, 1.0 and $1.5 \mathrm{~mm}$.

Critical overloads can be assessed in the same way. As already mentioned, optical microscopy of longitudinal sections near the fractured bars disclosed small cracks, between 0.3 and $0.5 \mathrm{~mm}$ depth. From Fig. 9, it can be deduced that a bar with a crack of $0.5 \mathrm{~mm}$ can carry a load of 0.90 uts. Bars with a crack depth of less than $0.3 \mathrm{~mm}$ are unaffected.

Cracks can also affect overstretching of the bars due to differential displacements between the ground anchorage and the exterior anchorage. Considering, again, damage in the form of a crack of $0.5 \mathrm{~mm}$ depth, from Fig. 9, the critical displacements can be inferred. If the bar is initially stressed at $40,60,70,80 \%$ of uts the critical displacements are, respectively, $9.5,6.6,3.7$ and $0.8 \mathrm{~mm}$.

This analysis reveals that bars with low values of fracture toughness are highly susceptible to damage [13-16]. The computed figures are indicative of the defect size, or overloads, the designer can assume in different working scenarios. Cracks can develop from notches under repeated loads, by fatigue or, in aggressive environments, due to stress corrosion cracking. Therefore, the following recommendations arise:

1. The bars will be more damage tolerant if their fracture toughness is increased. The fracture toughness should be required as an additional mechanical property that can be measured according to well established standards [4,5].

2. The bars will be more damage tolerant if they are properly protected against injuries, particularly corrosion. In this respect, knowledge of susceptibility to environmentally assisted cracking should be of great value to the designer.

3. The behaviour of cast-in-place and post-installed mechanical anchors associated with embedment failure has been studied in $[17,18]$ and embedment design provisions for these types of anchors seem to be incorporated in current building codes and design standards.

\section{Acknowledgements}

The authors gratefully acknowledge the technical support of Mr. César Guzmán from HCC S.A. (Hidráulica, Construcciones y Conservación).

They are also grateful to José Miguel Martínez and Rosa María Morera for their help with the artwork and typing.

\section{Appendix A}

Fatigue cracking does not work with materials as brittle and hard as that of the failed bars; the tests show that the specimen fracture frequently occurs before the local yielding necessary for fatigue cracking initiation. Therefore, only samples cracked by stress corrosion or stable fracture can be successfully used for fracture toughness assessment. The latter is the case of the SBS specimens described in Section 2.4 and that of one SEBS, all them unsuccessfully fatigue precracked. In this SEBS case, stable fracture propagation occurred. At macroscopic level an entire notch front did not form, a corner crack being detected before the specimen failure.

This cracked SEBS was fracture tested by loading according to the standard [4]. The stress intensity factor at fracture was calculated from [19], by identifying the cracked cross section of the SEBS to that of a flat plate in bending with a quarter 

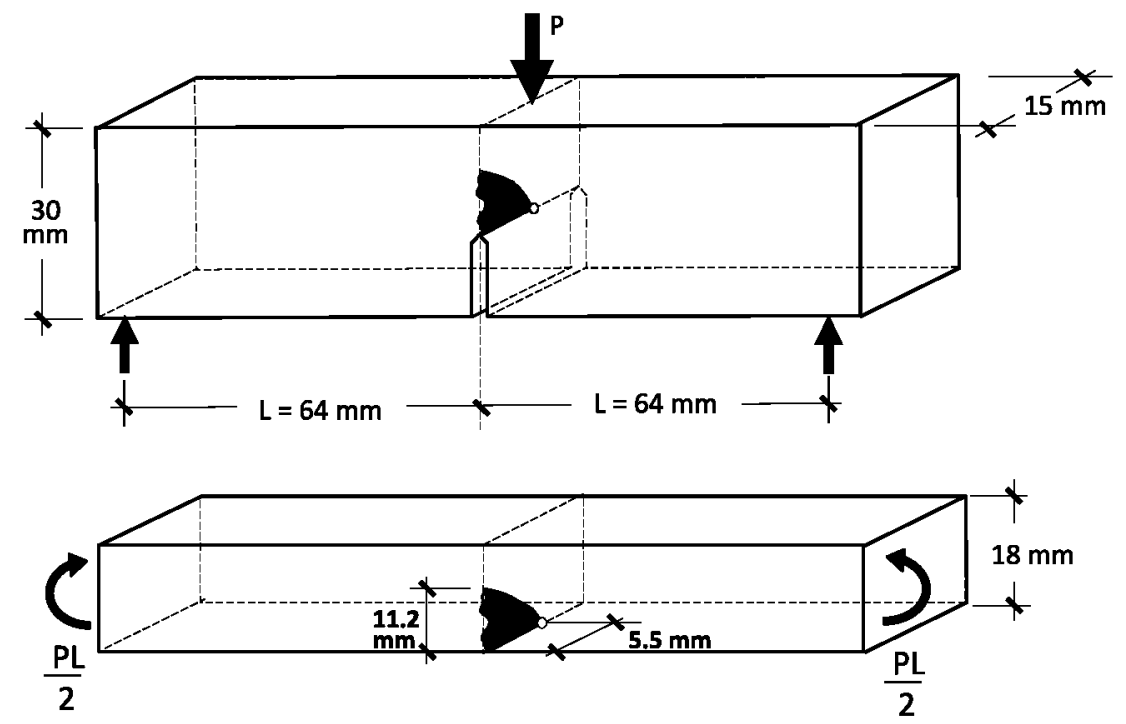

Fig. A1. Stress intensity factor determination from a corned cracked SEBS (dimensions in $\mathrm{mm}$ ).

elliptical corner crack (Fig. A1). The maximum stress intensity factor (SIF) resulting for a recorded failure load $P=8 \mathrm{kN}$, i.e., a failure bending moment of $256 \mathrm{Nm}$, was of $36 \mathrm{MPa} \mathrm{m}{ }^{1 / 2}$. It occurred at the deepest point of the crack front, as shown in Fig. A1. The value of the SIF obtained for the SEBS well matches the fracture toughness values found in SBS case.

\section{References}

[1] Krishnadev M, Larouche M, Lakshmanan V, Sridhar R. Fracture of high carbon high strength anchor rods. Eng Fail Anal 2008;15:1009-18.

[2] Valiente A, Elices M. Premature failure of prestressed steel bars. Eng Fail Anal 1998;5:219-27.

[3] ISO 15630-3: 2010 Steel for the reinforcement and prestressing of concrete - Test methods - Part 3: Prestressing steel.

[4] ASTM E 399-90. Standard test method for plane-strain fracture toughness of metallic materials.

[5] ASTM E 1304-97. Standard test method for plane-strain (Chevron notch) fracture toughness of metallic materials.

[6] Elices M, Caballero L, Valiente A, Ruiz J, Martín A. Hydrogen embrittlement of steels for prestressing concrete: The FIB and DIBt tests. NACE Corros J $2008 ; 64: 164-74$.

17] Astiz MA. PhD Thesis, Universidad Politécnica de Madrid, Escuela de Ingenieros de Caminos; 1976, http://oa.upm.es/677/.

[8] Astiz MA. An incompatible singular elastic element for two and three dimensional crack problems. Int J Fract 1986;31:105-23.

[9] Astiz MA, Elices M, Morton J, Valiente A. A photoelastic determination of stress intensity factor for an edge-cracked rod in tension. Soc Exp Stress Anal (SESA), Michigan Conference, USA; 1981, p. 277-82.

[10] Levan A, Royer J. Part-circular surface cracks in round bars under tension, bending and twisting. Int J Fract 1993;61:71-99.

[11] Toribio J, Alvarez N, González B, Mateos JC. A critical review of stress intensity factors for surface cracks in round bars subjected to tension loading. Eng Fail Anal 2009;16:794-809.

[12] Valiente A. PhD Thesis, Universidad Politécnica de Madrid; 1980, http://oa.upm.es/745/01/04198001.pdf.

[13] Gómez F], Elices M. A fracture criterion for blunted V-notched samples. Int J Fract 2004;127:239-64.

[14] Gómez F], Elices M. A fracture criterion for sharp V-notched samples. Int J Fract 2003;123:163-75.

[15] Gômez F], Guinea GV, Elices M. Failure criteria for linear elastic materials with U-notches. Int J Fract 2006;141:99-113.

[16] Gómez F], Elices M. Fracture of components with V-shaped notches. Eng Fract Mech 2003;70:1913-27.

[17] Eligehausen R, Balogh T. Behavior of fasteners loaded in tension in cracked reinforced concrete. ACI Struct J 1995;92(3):365-79.

[18] Fuchs W, Eligehausen R, Breen JE. Concrete capacity design (CCD) approach for fastening to concrete. ACl Struct J 1995;92(1):73-94

[19] Newman JC, Raju IS. Stress intensity factor equation for cracks in three-dimensional finite bodies subjected to tension and bending loads: NASA TM 85793. Hampton, VA, USA: NASA langley Research Center; 1983. 